\title{
Severidade da ferrugem da soja em função do suprimento de potássio e cálcio em solução nutritiva
}

\author{
Jadir Borges Pinheiro ${ }^{1}$ Edson Ampélio Pozza², Adélia Aziz Alexandre Pozza ${ }^{3}$, Alécio de Souza Moreira 4 , \\ Marcelo Carvalho Alves ${ }^{5}$
}

\begin{abstract}
RESUMO
Entre as estratégias para o controle da ferrugem da soja cita-se a nutrição mineral equilibrada. Objetivou-se, neste trabalho, verificar o efeito do cálcio e do potássio na severidade da ferrugem (Phakopsora pachyrhizi), na fotossíntese potencial e na nutrição de plantas de soja. O delineamento experimental foi em blocos casualizados, com 25 tratamentos, 4 repetições e 2 plantas por repetição. Utilizou-se esquema fatorial 5 x 5 , com 5 doses de $\mathrm{K}(4,5,6,7,8$ mmol L-1), combinadas com 5 doses de $\mathrm{Ca}\left(3,5,7,9,11 \mathrm{mmol} \mathrm{L}^{-1}\right)$. As plantas foram inoculadas no estádio V4 e, após nove dias, iniciaram-se avaliações da severidade da ferrugem pelas porcentagens de tecido lesionado, as quais foram transformadas em área abaixo da curva de progresso da doença (AACPS).Também foram avaliados a fotossíntese potencial e o teor de nutrientes na matéria seca de raiz, caule e folhas. O suprimento de Ca reduziu a AACPS em todas as doses de K. O suprimento de K também reduziu a AACPS nas doses 5, 7 e $11 \mathrm{mmol} \mathrm{L}^{-1}$ de Ca. A menor AACPS foi observada na combinação das doses de 8 e $11 \mathrm{mmol} \mathrm{L}^{-1}$ de $\mathrm{K}$ e Ca, enquanto a maior AACPS foi observada nas doses de 4 e $5 \mathrm{mmol}$ $\mathrm{L}^{-1}$ de $\mathrm{Ke} \mathrm{Ca}$. As plantas tratadas com as doses 6 e $5 \mathrm{mmol} \mathrm{L}^{-1}$ de $\mathrm{K}$ e Ca e 5 e $5 \mathrm{mmol} \mathrm{L}^{-1}$ de $\mathrm{K}$ e Ca apresentaram melhor resposta fotossintética. Com o incremento das doses de $\mathrm{K}$ na solução, houve aumento dos teores foliares de $\mathrm{K}$ e redução linear dos teores foliares de $\mathrm{Ca}$. Com o incremento das doses de $\mathrm{Ca}$ em solução nutritiva verificaram-se aumentos nos teores desse elemento e redução linear dos teores de K nas folhas.
\end{abstract}

Palavras-chave: Phakopsora pachyrhizi, nutrição mineral, fotossíntese.

\section{ABSTRACT}

\section{Effect of potassium and calcium supplied via nutrient solution on the severity of Asian soybean rust}

A balanced mineral nutrition is among the strategies for the control of Asian soybean rust. This work aimed to evaluate the severity of the soybean rust (Phakopsora pachyrhizi), the potential photosynthesis and the nutrition of soybean plants with different levels of $\mathrm{K}$ and $\mathrm{Ca}$. The experiment was arranged in a randomized block design with 25 treatments, 4 repetitions and 2 plants per repetition. A 5 x 5 factorial scheme with 5 doses of $\mathrm{K}\left(4,5,6,7,8 \mathrm{mmol} \mathrm{L}^{-1}\right)$ combined with 5 doses of $\mathrm{Ca}\left(3,5,7,9,11 \mathrm{mmol} \mathrm{L}^{-1}\right)$ was used. Plants were inoculated at growth stage V4 and after nine days weekly evaluations of disease severity were carried out using percentage of injured tissues, which were transformed into area under the disease progress curve (AUDPCS). Potential photosynthesis and nutrient content in the root, stem and leaf dry matter were also evaluated. The supply of Ca reduced AUDPCS at all doses of K. The supply of K also

\footnotetext{
Recebido para publicação em março de 2009 e aprovado em dezembro de 2010

'Engenheiro Agrônomo, Doutor. Laboratório de Nematologia, CNPH/EMBRAPA. Rodovia BR-060 Km 09, 70359-970, Brasilia, DF, Brasil. Caixa Postal 218. jadirborges@ hotmail.com

2 Engenheiro Agrônomo, Doutor. Departamento de Fitopatologia, UFLA, Caixa Postal 3037, 37200-000, Lavras, MG. eapozza@dfp.ufla.br

${ }^{3}$ Engenheira Agrônoma, Doutor. Campus de Florestal, UFV, 35690-000, Florestal, MG, Brasil. adelia.pozza@ufv.br

${ }^{4}$ Engenheiro Agrônomo. Departamento de Fitopatologia e Nematologia, ESALQ, Av. Pádua Dias, 11, 13418-900, Piracicaba, SP, Brasil. aleciomoreira@esalq.usp.br

Engenheiro Agrônomo, Doutor. Departamento de Solos e Engenharia Rural/FAMEV, UFMT, Av. Fernando Corrêa da Costa, s/n, Campus Coxipó, 78060-900, Cuiaba, MT, Brasil marcelocalves@ufmt.br
} 
reduced the AUDPCS at the doses of 5,7 and $11 \mathrm{mmol} \mathrm{L}^{-1}$ of $\mathrm{Ca}$. The smallest AUDPCS was observed at the combination 8 and $11 \mathrm{mmol} \mathrm{L}^{-1}$ of $\mathrm{K}$ and $\mathrm{Ca}$, respectively, while the largest AUDPCS was observed at the doses of 4 and $5 \mathrm{mmol} \mathrm{L}^{-}$ ${ }^{1}$ of $\mathrm{K}$ and $\mathrm{Ca}$. The plants treated with 6 and $5 \mathrm{mmol} \mathrm{L}^{-1}$ of $\mathrm{K}$ and $\mathrm{Ca}$ and 5 and $5 \mathrm{mmol} \mathrm{L}^{-1}$ of $\mathrm{K}$ and $\mathrm{Ca}$ showed better photosynthetic response. Increasing doses of $\mathrm{K}$ in the solution promoted increase in $\mathrm{K}$ leaf contents and linear decrease in $\mathrm{Ca}$ leaf levels. Increasing the levels of $\mathrm{Ca}$ in nutrient solution promoted an increase in the content of this element and a linear reduction of $\mathrm{K}$ levels in the leaves.

Key words: Phakopsora pachyrhizi, mineral nutrition, photosynthesis.

\section{INTRODUÇÃO}

Em função da fácil disseminação pelo vento, a ferrugem asiática da soja (Phakopsora pachyrhizi Sydow \& P. Sydow) pode ser encontrada em praticamente todas as regiões produtoras do Brasil, causando reduções de até $75 \%$ na produtividade (Almeida et al., 2005). A pulverização com fungicidas é a principal medida de controle da ferrugem, entretanto, a nutrição mineral pode contribuir para reduzir a intensidade da doença (Marschner, 1995). Isto é, a nutrição mineral favorece o aumento na espessura da camada de cera da lamela média, e a produção de compostos fenólicos, dentre outros fatores (Huber, 2002) que aumentam a resistência das plantas às doenças. A deficiência dos nutrientes necessários para sintetizar compostos químicos e barreiras físicas, ao redor do ponto de infecção, pode resultar em susceptibilidade do hospedeiro (Marschner, 1995).

Entre os nutrientes minerais essenciais, o potássio e o cálcio têm grande importância em respostas de defesa de plantas a fitopatógenos (Malavolta, 2006). O potássio é considerado um dos nutrientes de maior efeito benéfico para a sanidade da maioria das espécies vegetais (Perrenoud, 1990). Esse nutriente desempenha papel fundamental em muitas reações do metabolismo. O potássio aumenta a espessura da parede celular em células da epiderme, promove rigidez da estrutura dos tecidos e regula o funcionamento dos estômatos, além de contribuir para a recuperação de tecidos que sofreram injúrias (Huber \& Arny, 1985; Marschner, 1995). No caso de patógenos biotróficos, como as ferrugens, pode ajudar a recuperar os tecidos colonizados, após o término da infecção, por aplicação de fungicidas curativos ou por ação de fatores ambientais desfavoráveis ao patógeno.

O Ca pode afetar a incidência ou a severidade de doenças de plantas de duas maneiras. Primeiro, porque contribui para a estabilidade de biomembranas; assim, sob baixos teores de $\mathrm{Ca}$, há aumento do efluxo de compostos de baixo peso molecular, como açúcares, do citoplasma celular para o apoplasto, favorecendo os fitopatógenos.
(Marschner, 1995). Além dessa função, o Ca tem papel crítico na divisão e no desenvolvimento celular, na estrutura da parede celular e na formação da lamela média (Malavolta, 2006; Epstein \& Bloom, 2004; Huber, 2002). Muitos fungos e bactérias fitopatogênicas invadem os tecidos, produzindo enzimas pectinolíticas extracelulares, como a poligalacturonase (McGuire \& Kelman, 1986), a qual dissolve a lamela média das plantas hospedeiras. A atividade dessa enzima é drasticamente inibida pela presença de cálcio (Bateman \& Lumsden, 1965, Marschner, 1995).

Conhecer os efeitos desses nutrientes minerais sobre a intensidade da ferrugem da soja pode auxiliar a elaborar estratégias de manejo e, consequentemente, reduzir as aplicações de defensivos agrícolas, o custo de produção e o impacto ambiental. Dessa forma, o objetivo deste trabalho foi verificar o efeito do cálcio e do potássio, em solução nutritiva, na severidade da ferrugem, na fotossíntese potencial e na nutrição de plantas de soja.

\section{MATERIAL E MÉTODOS}

O experimento foi instalado e conduzido em casa de vegetação do Departamento de Fitopatologia da Universidade Federal de Lavras, em altitude de 918 metros, latitude Sul de $21^{\circ} 14^{\prime}$ longitude Oeste de $45^{\circ} 00^{\prime}$, no período de fevereiro a abril de 2006.

Para produzir o inóculo, foi semeado o cultivar MG BR-46 (Conquista), susceptível à ferrugem da soja, diretamente nos vasos plásticos, contendo $5 \mathrm{~kg}$ de Latossolo Vermelho distroférrico (LVdf), mantendo-se 2 plantas por vaso. As plantas receberam adubação básica, nas seguintes doses, em mg dm${ }^{-3}$ : P, 200 (MAP), K, $150(\mathrm{KCl}), \mathrm{S}, 50$ $\left(\mathrm{K}_{2} \mathrm{SO}_{4}\right), \mathrm{B}, 0,5\left(\mathrm{H}_{3} \mathrm{BO}_{3}\right), \mathrm{Co}, 0,01\left(\mathrm{CoCl}_{2} \cdot \mathrm{H}_{2} \mathrm{O}\right), \mathrm{Cu}, 1,5$ $\left(\mathrm{CuSO}_{4} \cdot 5 \mathrm{H}_{2} \mathrm{O}\right), \mathrm{Mo}, 0,1\left(\mathrm{H}_{2} \mathrm{MoO}_{4}\right), \mathrm{Mn}, 3,5\left(\mathrm{MnSO}_{4} \cdot \mathrm{H}_{2} \mathrm{O}\right)$ e Zn, 5,0 $\left(\mathrm{ZnSO}_{4} \cdot 7 \mathrm{H}_{2} \mathrm{O}\right)$, conforme sugestão de Malavolta (1980) para experimentos em vasos conduzidos em casa de vegetação. Aos 35 dias após a emergência, as plantas foram inoculadas com suspensão de $1 \mathrm{mg}$ de urediniósporos de $P$. pachyrhizi $/ \mathrm{ml}$ de água + tween 20 a $0,05 \%$, preparada no momento da pulverização (Vale, 1985). A 
inoculação foi realizada na face inferior dos folíolos já completamente expandidos. Em seguida, as plantas foram cobertas com saco plástico, com o intuito de promover câmara úmida, por $12 \mathrm{~h}$. Essas plantas foram mantidas em casa de vegetação para a coleta de urediniósporos, os quais foram armazenados em nitrogênio líquido $\left(-196^{\circ} \mathrm{C}\right)$ para inoculação.

As plantas de soja do cultivar MG BR-46 (Conquista), para o cultivo em solução nutritiva, foram semeadas em vermiculita. Após a emergência, as plântulas foram transferidas para bandejas com capacidade para $10 \mathrm{~L}$, contendo solução básica de Hoagland (Hoagland \& Arnon, 1950), a 50\% da força iônica e sob aeração contínua, realizada com o auxílio de um conjunto compressor, kitasato e mangueiras, onde permaneceram por 10 dias para adaptação. Após esse período, as mudas foram selecionadas por tamanho e transplantadas duas mudas por recipiente plástico com capacidade para 3,5 L, pintados com tinta reflexiva, contendo solução de Hoagland modificada por Tuite (1969): N (15 mmol L-1), P (1 mmol L-1), K (6 mmol L $\left.{ }^{1}\right), \mathrm{Ca}\left(5 \mathrm{mmol} \mathrm{L}^{-1}\right), \mathrm{Mg}\left(2 \mathrm{mmol} \mathrm{L}^{-1}\right), \mathrm{S}\left(2 \mathrm{mmol} \mathrm{L}^{-1}\right)$ e com os micronutrientes: B $\left(46 \mu\right.$ mol. $\left.\mathrm{L}^{-1}\right), \mathrm{Cu}\left(0,3 \mu \mathrm{mol} . \mathrm{L}^{-1}\right), \mathrm{Fe}(89,6$

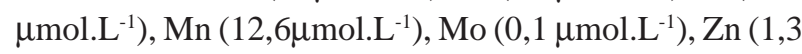
$\mu$ mol. $\left.L^{-1}\right)$, a $100 \%$ da força iônica, com os devidos tratamentos, recebendo aeração constante. Os tratamentos consistiram em cinco doses de $\mathrm{K}\left(4,5,6,7\right.$ e $\left.8 \mathrm{mmol} \mathrm{L}^{-1}\right)$, combinadas, em esquema fatorial, com cinco doses de $\mathrm{Ca}$ (3, 5, 7, 9 e $\left.11 \mathrm{mmol} \mathrm{L}^{-1}\right)$. O delineamento experimental utilizado no ensaio foi o de blocos casualizados, com 25 tratamentos (fatorial 5X5) e 4 repetições, sendo cada recipiente plástico, com duas plantas, considerado uma unidade experimental.

Três vezes por semana, realizou-se monitoramento do $\mathrm{pH}$ da solução nutritiva, mantendo-o entre 5,0 e 5,5 com a adição de $\mathrm{HCl}$ 0,1 mol.L ${ }^{-1}$ ou $\mathrm{NaOH} \mathrm{0,1} \mathrm{mol.L}{ }^{-1}$. Quando necessário, o volume dos vasos foi completado com água deionizada. A troca da solução nutritiva foi realizada nos diferentes tratamentos, quando a condutividade elétrica atingiu 30\% do valor inicial (Pozza, 1999).

A inoculação das plantas foi realizada no estádio V4 com suspensão de 2,0 x $10^{4}$ urediniósporos $\mathrm{ml}^{-1} \mathrm{em}$ dois pares de folhas trifolioladas, na face inferior dos folíolos. A seguir as plantas foram cobertas com saco plástico por $12 \mathrm{~h}$, sob temperatura de $22,4^{\circ} \mathrm{C}$, em casa de vegetação.

Nove dias após a inoculação, iniciou-se a avaliação da doença (estádio V6 - $5^{\text {a }}$ folha trifoliada completamente desenvolvida). Foi avaliada a severidade da ferrugem, sendo realizadas seis avaliações, em intervalos semanais. A severidade foi quantificada pela porcentagem de tecido lesionado, de acordo com a escala de Bromfield (1984), em folíolos centrais de trifólios do terço médio das plantas. Para isso os folíolos foram marcados, e, após seis avaliações, calculou-se a área abaixo da curva de progresso da doença em cada tratamento (Shaner \& Finney, 1977).

Ao término das avaliações, as folhas, os caules e as raízes foram lavados em água destilada, acondicionados separadamente em sacos de papel e secos em estufa, a $60^{\circ} \mathrm{C}$, até atingirem massa constante. Procedeu-se a pesagem e a moagem de caule e folhas, separadamente, e a pesagem das raízes. Em seguida, determinaram-se os teores de cálcio e de potássio, por digestão via seca de cada amostra de caule e folhas, seguindo metodologia descrita por Malavolta et al. (1997). As concentrações de Ca e de $\mathrm{K}$ foram determinadas por espectrofotometria de absorção atômica e de chama, respectivamente.

A fotossíntese potencial foi determinada pelo método de evolução do oxigênio, utilizando-se câmara de Clark de fase gasosa (Hansatech), com eletrodo de oxigênio acoplado a uma caixa de controle de fluxo elétrico (Hansatech), seguindo a metodologia utilizada por Delieu \& Walker (1983), com as seguintes alterações: solução de $\mathrm{KCl}$ saturada e $\mathrm{NaHCO}_{3}\left(1 \mathrm{~mol} \mathrm{~L}^{-1}\right)$. As medições foram realizadas à temperatura de $22{ }^{\circ} \mathrm{C}$ e 1.200 ìmol m² s-1 de densidade de fluxo de fótons fotossinteticamente ativos (DFFFA). A determinação do volume da câmara foi realizada com método de injeção (Delieu \& Walker, 1981). Como fonte de DFFFA, utilizou-se uma lâmpada de halogênio e o controle foi realizado por quantômetro, acoplado a um porômetro (modelo 1600M; LI-COR, Lincoln.Neb). Para cada tratamento, foram realizadas três determinações fotossintéticas (repetições), sendo cada repetição constituída por 1 folha por planta, do terço médio, da qual retirou-se disco foliar de $10 \mathrm{~cm}^{2}$.

O monitoramento da temperatura e da umidade relativa do ar na casa de vegetação foi realizado durante toda a condução do ensaio, com termoigrógrafo, localizado em abrigo climatológico.

A análise de variância e o ajuste de modelos, cujos resultados foram significativos, no teste $\mathrm{F}$, considerando-se significância fixada em 5\%, foram realizados com o programa Sisvar $^{\circledR}$ - versão 4.6 (Build 6.1). As variáveis quantitativas foram submetidas à análise de regressão polinomial. Em seguida, foram plotadas as curvas e as superfícies de resposta, com seus respectivos cortes. Os pontos de máximo e, ou, de mínimo, foram obtidos a partir da derivada de primeira ordem de cada equação, as quais foram igualadas a zero.

\section{RESULTADOS E DISCUSSÃO}

As condições ambientais durante a condução do experimento foram favoráveis ao progresso da ferrugem em casa de vegetação. Observaram-se umidade relativa e temperatura média, durante todo experimento, de $71,2 \%$ e $25^{\circ} \mathrm{C}$, 
respectivamente. As temperaturas médias máximas e médias mínimas foram de $30,4^{\circ} \mathrm{C}$ e de $19,7^{\circ} \mathrm{C}$, respectivamente (Figura 1). Segundo Reis \& Bresolin (2004), para que se desenvolva epidemia severa é necessário período de molhamento foliar de, aproximadamente, 10 horas por dia e temperaturas de $18^{\circ} \mathrm{C}$ a $26^{\circ} \mathrm{C}$. Temperaturas acima de $30^{\circ} \mathrm{C}$ e abaixo de $15^{\circ} \mathrm{C}$ e seca retardam o progresso da doença. Portanto, as condições consideradas favoráveis ao progresso da epidemia, por esses autores, foram atendidas nesse experimento, exceto para a temperatura média máxima, a qual poderia ter atrasado o progresso da doença. Entretanto, Kochman (1979), em estudo sobre o progresso da ferrugem da soja, com diferentes regimes de temperaturas, em casa de vegetação, concluiu que a ferrugem da soja progride numa ampla faixa de temperaturas e considerou a faixa de $17^{\circ} \mathrm{C}$ a $27^{\circ} \mathrm{C}$ como a mais favorável. Além disso, observou-se nesse experimento, alta severidade da ferrugem em alguns tratamentos

Para área abaixo da curva de progresso da severidade (AACPS) da ferrugem asiática, houve interação entre as doses de $\mathrm{K}$ e $\mathrm{Ca}$ (Figura 2). O suprimento de Ca reduziu a AACPS em todas as doses de K. O suprimento de K também reduziu a AACPS, nas doses 5, 7 e $11 \mathrm{mmol} \mathrm{L}^{-1} \mathrm{de}$ Ca. Dessa forma, o K reduziu a AACPS somente quando o suprimento de $\mathrm{Ca}$ foi adequado, isto é, nas maiores doses de Ca adicionadas. Quando esse suprimento é baixo, a adição de $\mathrm{K}$ aumenta a AACPD, confirmando teorias sugeridas por Malavolta (1980), Pozza et al., (2001) e Garcia Júnior et al., (2003).

A menor AACPS $(22,63)$ foi observada na combinação das doses de 8 e $11 \mathrm{mmol} \mathrm{L}^{-1}$ de $\mathrm{K}$ e Ca, respectivamente, enquanto a maior AACPS $(99,88)$ foi observada nas doses de 4 e $5 \mathrm{mmol} \mathrm{L}^{-1}$ de $\mathrm{K}$ e Ca, respectivamente. A porcentagem de redução da AACPS em decorrência da interação potássio-cálcio, em relação às menores doses combinadas, foi de $86,65 \%$. Essa redução da severidade da ferrugem da soja também foi constatada por Balardin et al. (2006), em vasos com solo em casa de vegetação, em função de doses de potássio $\left(0,35,70\right.$ e $\left.140 \mathrm{~kg} \mathrm{ha}^{-1}\right)$ e de fósforo $\left(0,42,5,85\right.$ e $\left.170 \mathrm{~kg} \mathrm{ha}^{-1}\right)$. Os autores observaram influência mais pronunciada do $\mathrm{K}$, em relação a do $\mathrm{P}$, em baixa severidade e taxa de progresso da ferrugem. Como o experimento foi realizado em solo, a maior solubilidade do $\mathrm{K}$ nesse ambiente tornou este nutriente mais facilmente absorvido pelas raízes do que o $\mathrm{P}$, o qual reage com as partículas do solo, tornando-se menos disponível na solução do solo. Esse fato não pôde ser verificado neste experimento, por este ter sido realizado em solução nutritiva, na qual todos os nutrientes adicionados encontramse disponíveis para serem absorvidos pelas plantas. Entretanto, como o patossistema é semelhante, algumas comparações podem ser feitas entre os experimentos, pois semelhante a este, a menor severidade da ferrugem tam-

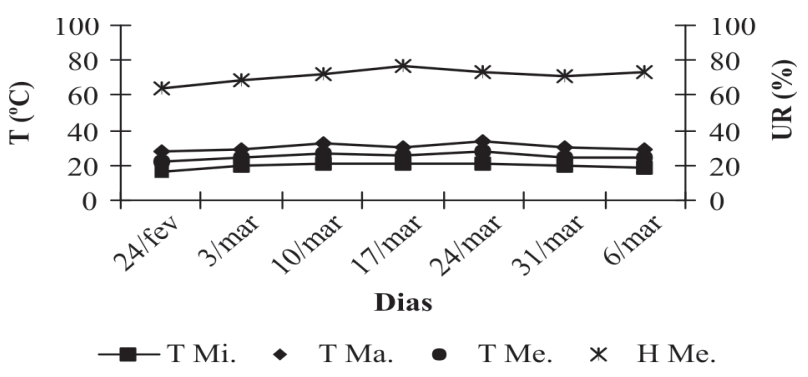

Figura 1. Variação da temperatura $(\mathrm{T})$ e da umidade relativa do ar (UR) em casa de vegetação, durante condução do ensaio.

\section{$\mathrm{Z}=88,0883+10,2057 \mathrm{Ca}-6,0919 \mathrm{~K}-1,3745 \mathrm{~K}^{2}$ \\ $+0,0658 \mathrm{CaK}+0,0002 \mathrm{Ca}^{2} \quad \mathrm{R}^{2}=0,77$}

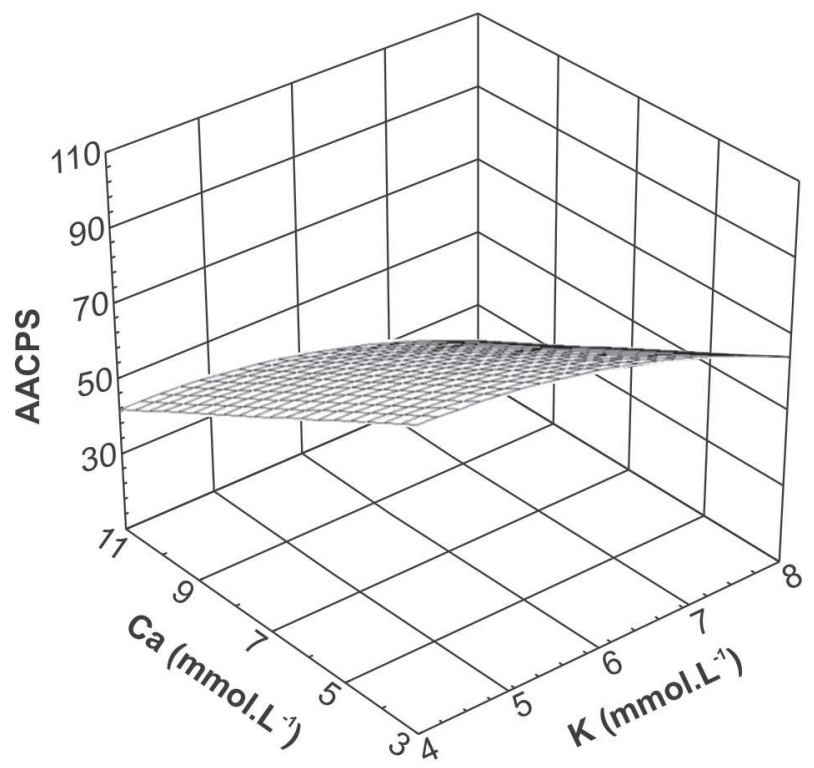

Figura 2. Área abaixo da curva de progresso da severidade da ferrugem asiática, em função das doses de potássio e cálcio aplicadas em solução nutritiva.

bém foi observada na maior quantidade de $\mathrm{K}$ adicionado ao solo (140 kg ha-1 de K), com redução de 71,84 a 70,63\%, nos estádios de desenvolvimento da cultura, V2 e R5, respectivamente. $\mathrm{Na}$ adubação equilibrada entre $\mathrm{P}$ e K, houve menor severidade da ferrugem. De forma geral, o fornecimento equilibrado de potássio à planta diminui a incidência de doenças, em razão do aumento da resistência à penetração e desenvolvimento de alguns patógenos. Além de aumentar a espessura da parede celular, o potássio proporciona maior rigidez dos tecidos, regulação funcional dos estômatos e promove a rápida recuperação dos tecidos que sofreram injúria (Huber \& Arny, 1985; Marschner, 1995; Basseto et al., 2007). O uso da fertilização adequada em K, aliado à resistência varietal, a técnicas culturais e de proteção de plantas, reduziu linearmente o nível da incidência da queima foliar da soja (Cercospora kikuchii (T. Matsu \& Tomoyasu) Chupp.), segundo Ito et al. (1993). O aumento das doses de K de 0 para $600 \mathrm{~kg} \mathrm{ha}^{-1}$ 
de $\mathrm{K}_{2} \mathrm{O}$ reduziu em 21,67 \% a incidência, embora não tenha sido observada relação com outros nutrientes.

Existem relatos do efeito do $\mathrm{K}$ também em outros patossistemas. A intensidade da cercosporiose do cafeeiro (Cercospora coffeicola Berkeley \& Cooke) foi influenciada pelo suprimento de $\mathrm{K}\left(1,3,5\right.$ e $\left.7 \mathrm{mmol} \mathrm{L}^{-1}\right)$ e $\mathrm{Ca}(2,4$, 6 e $8 \mathrm{mmol} \mathrm{L}^{-1}$ ) em solução nutritiva (Garcia Júnior et al., 2003). A menor área abaixo da curva de progresso do total de lesões (AACPTL) foi obtida com as doses $7 \mathrm{mmol} \mathrm{L}^{-1}$ de $\mathrm{Ke}$ e,35 mmol L-1 de Ca. A redução da AACPTL com o aumento das doses de $\mathrm{Ca}$, da mesma forma que neste experimento (Figura 2), evidenciou a importância desse nutriente na constituição da lamela média celular.

Para a severidade da murcha-de-curtobacterium (Curtobacterium flaccumfaciens pv. flaccumfaciens (Hedges) Collins \& Jones) em feijoeiro em casa de vegetação, Theodoro \& Maringoni (2006), avaliando o efeito de doses de $\mathrm{K}\left(45,67,5,90,112,5\right.$ e $\left.135 \mathrm{~kg} \mathrm{ha}^{-1} \mathrm{de} \mathrm{K}_{2} \mathrm{O}\right)$, verificaram que não houve influência das doses de $\mathrm{K}$ na área abaixo da curva de progresso da doença. Apesar de o K ser frequentemente associado à redução da intensidade de doenças de plantas, esse efeito não pode ser generalizado, pois pode variar em função da sua disponibilidade no solo e da interação com outros nutrientes, das condições ambientais, da susceptibilidade da planta e do patógeno envolvido. Outro aspecto é que, segundo Marschner (1995), o efeito do K na redução de doenças ocorre em plantas com deficiência desse nutriente, podendo não ser notado em plantas suficientemente nutridas com $\mathrm{K}$, mesmo com o aumento da adubação. Assim, na maioria dos casos, o efeito do potássio está confinado à faixa de deficiência. Em plantas deficientes, a síntese de compostos de alto peso molecular (proteínas, amido e celulose) é impedida e acumulam-se compostos orgânicos de baixo peso molecular (Malavolta, 2006). Na faixa de deficiência, a elevação no suprimento de potássio leva ao decréscimo no conteúdo de compostos orgânicos de baixo peso molecular e aumenta o desenvolvimento da planta até um ponto máximo, em que o aumento adicional no nível de potássio não tem efeito substancial nos compostos orgânicos (Marschner, 1995) e, provavelmente, também não afeta a resistência da planta aos patógenos

Em relação ao Ca, Edgington \& Walker (1958) relataram a redução da severidade de doenças com a utilização desse nutriente. Esses autores estudaram o efeito do cálcio, em solução nutritiva, na murcha de Fusarium em plantas de tomate, e verificaram redução na severidade da doença com o aumento da concentração desse nutriente, na solução, de 5 para $500 \mathrm{mg} \mathrm{L}^{-1}$. Corden (1965) também observou comportamento semelhante no mesmo patossistema. Segundo o autor, as reduzidas concentrações de $\mathrm{Ca}^{+2}$ presentes nos tecidos vegetais não foram capazes de inibir a atividade da poligalacturonase, produzida pelo patógeno. A presença de cátions $\mathrm{Ca}^{2+}$ no tecido foliar, respeitando a quantidade ideal de K no conteúdo celular, inibe drasticamente a ação de enzimas pectolíticas produzidas por muitas doenças de etiologia fúngica, cuja função é dissolver a lamela média da parede celular. Além disso, na própria lamela média, na superfície externa da membrana plasmática, no retículo endoplasmático e nos vacúolos, são encontradas altas concentrações de Ca, comprovando o envolvimento desse elemento na integridade dos tecidos vegetais (Marschner, 1995; Malavolta, 2006; Garcia Júnior et al., 2003).

$\mathrm{Na}$ avaliação da fotossíntese potencial, os tratamentos com melhor resposta fotossintética à intensidade luminosa foram os de 6 e $5 \mathrm{mmol} \mathrm{L}^{-1}$ de $\mathrm{Ke}$ Ca e 5 e $5 \mathrm{mmol} \mathrm{L}^{-1}$ de $\mathrm{Ke}$ $\mathrm{Ca}$, respectivamente. Para os demais tratamentos, não houve diferenças significativas (Figura 3). Esses tratamentos com maior resposta fotossintética apresentaram também os maiores valores de severidade (2,82 e 2,57\% de tecido lesionado, respectivamente) em relação aos demais $(1,72 ; 1,19$ e $0,71 \%$ de tecido lesionado, para 7 e $7 ; 8$ e 9; 8 e $11 \mathrm{mmol} \mathrm{L}^{-1}$ de $\mathrm{Ke} \mathrm{Ca}$, respectivamente). A maior fotossíntese potencial, observada nos tratamentos com maior porcentagem de severidade, pode ser decorrente do efeito compensatório, ou seja, como o patógeno é biotrófico, não rompe a membrana celular durante a colonização, houve aumento na fotossíntese para compensar a infecção, para atender tanto às necessidades do metabolismo das células dos vegetais quanto às do patógeno. $\mathrm{O} \mathrm{K}$, em níveis adequados, regula a abertura e o fechamento dos estômatos nas células-guarda e a turgidez do tecido, criando condições favoráveis para as reações da fotossíntese e outros processos metabólicos (Sfredo \& Panizzi, 1990). A maior taxa fotossintética, observada em plantas com maior severidade de ferrugem, também pode ser justificada pelo estímulo inicial que a doença causa na planta. De acordo com Pascholati \& Leite (1995), ocorre um aumento da atividade fotossintética no início do processo da doença, por um período reduzido, seguido, invariavelmente, pela redução da taxa de fotossíntese, por causa do aumento do surgimento de áreas cloróticas.

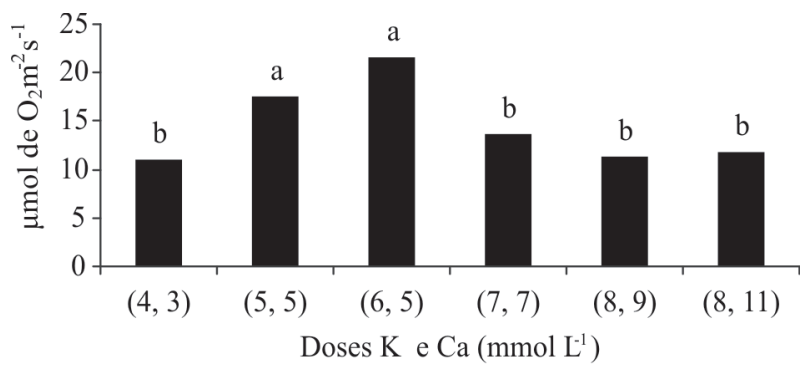

Figura 3. Fotossíntese potencial de plantas de soja inoculadas com esporos de $P$. pachyrhizi, em função de doses de potássio e cálcio (K, Ca) em solução nutritiva. Média seguidas da mesma letra não diferem entre si pelo teste de Scott Knott a 5\% de probabilidade. 
Também, como regulador móvel da atividade de enzimas, o K está envolvido essencialmente em todas as funções celulares, incluindo fosforilação, síntese de proteínas, translocação, redução de nitratos e fotossíntese. O nível equilibrado de $\mathrm{K}$ pode ter induzido o espessamento da parede celular, o acúmulo de aminoácidos e a produção de novos tecidos; entretanto seriam necessárias mais investigações com microscopia eletrônica de varredura para comprovar essa hipótese. Com maior densidade estomática, ocorreu maior assimilação de $\mathrm{CO}_{2}$, favorecendo de maneira positiva a fotossíntese potencial. Este nível depende da disponibilidade de $\mathrm{Mg}$ e de $\mathrm{Ca}$ (Huber, 2002) presentes em doses adequadas nestes tratamentos.

Para matéria seca das raízes, caule e folhas, não houve diferenças significativas na interação potássio-cálcio. Também não se observou efeito isolado das doses de K e Ca para essas variáveis. Segundo Sfredo \& Panizzi (1990), o ponto de maior acúmulo de matéria seca em plantas de soja ocorre aos 96 dias após emergência, e, neste ensaio, as plantas foram colhidas aos 52 dias após a montagem do experimento (estádio R2-R3), não atingindo o período no qual o crescimento é acelerado. Ventura (1987) também não verificou respostas significativas da soja com relação à altura das plantas e à produção de matéria seca das folhas e dos caules, quando diferentes doses de $\mathrm{K}\left(117,234\right.$ e $\left.351 \mathrm{mg} \mathrm{dm}^{-3}\right)$, Ca (100, 200 e $300{\mathrm{mg} . \mathrm{dm}^{-3}}^{-3}$ e $\mathrm{Mg}\left(24,48\right.$ e $72 \mathrm{mg} \mathrm{dm}^{-3}$ ) foram aplicadas no substrato. Nesse trabalho, as plantas foram colhidas no estádio recomendado para realizar as análises químicas foliares. Provavelmente, se elas tivessem sido colhidas mais tarde, poderiam ter sido observadas diferenças significativas para a matéria seca.

Apesar da elevada exigência em $\mathrm{K}$, existem poucos trabalhos nos quais se observaram respostas à adubação potássica, em relação à matéria seca. Assim, a resposta ao $\mathrm{K}$ na produção vegetativa, geralmente, ocorre em solos com reduzida disponibilidade do elemento. Contudo, por causa da grande capacidade da soja em extrair K do solo, a produção de material seco pode não ser ampliada pela adubação potássica, mesmo naqueles solos com reduzida disponibilidade do nutriente (Rosolem et al., 1993).

$\mathrm{O}$ teor de $\mathrm{Ca}$ no caule e nas folhas apresentou respostas semelhantes, com o incremento das doses de $\mathrm{Ca}$. Houve aumento no teor desse cátion no caule e folhas, de acordo com incremento das doses de Ca (Figura 4 A e 4 B). Esse resultado era esperado, pois, aumentando-se as doses de Ca na solução nutritiva, aumentou-se o teor desse elemento nas folhas e no caule.

A elevação das doses de K em solução nutritiva reduziu em 26,4\% os teores de Ca nas folhas (Figura 5A), indicando a competição entre esses cátions.

A elevação das doses de $\mathrm{Ca}$ em solução reduziu em $16,4 \%$ os teores de $\mathrm{K}$ nas folhas (Figura 5B), confirmando a competição entre cátions e destacando a menor influência do Ca sobre o $\mathrm{K}$, comparada à do $\mathrm{K}$ sobre o $\mathrm{Ca}$.

Essa redução pode ser explicada pela competição, entre estes dois cátions, pelo mesmo sítio de absorção das raízes. O equilíbrio entre os nutrientes $\mathrm{K}$ e Ca é importante na nutrição das plantas, verificando-se o antagonismo entre eles, pois o desequilíbrio de concentração provoca influências recíprocas em termos de disponibilidade no solo, absorção e translocação na planta (Garcia Júnior et al., 2003; Malavolta, 2006; Marschner, 1995).

Os teores de $\mathrm{K}$ nos tecidos do caule e das folhas foram afetados, significativamente, com o incremento das doses de K. No caule, observou-se aumento no teor de K, com o incremento das doses desse elemento na solução (Figura 6A). Comportamento semelhante foi observado nas folhas, em que houve ligeiro aumento linear no teor de $\mathrm{K}$, com o incremento das doses desse elemento de 4 para $8 \mathrm{mmol} \mathrm{L}^{-1}$ na solução (Figura $6 \mathrm{~B}$ ). O K no solo é facilmente lixiviado, podendo haver falta desse nutriente por fornecimento na época inadequada. Por outro lado, o Ca é pouco móvel no solo, sendo fornecido via calcário, o qual nem sempre é incorporado devidamente, promovendo ainda um maior desequilíbrio entre esses cátions e favorecendo o aumento da ferrugem asiática.

$\mathrm{O}$ antagonismo entre $\mathrm{Ca}$ e $\mathrm{K}$ também foi observado por Oliveira et al. (2001), no período de florescimento da soja. Os teores de $\mathrm{K}$, Ca e Mg nas folhas foram influenciados significativamente pela aplicação de Ca. Enquanto os teores de $\mathrm{Ca}$ e $\mathrm{Mg}$ foram aumentados, o teor de $\mathrm{K}$ foi
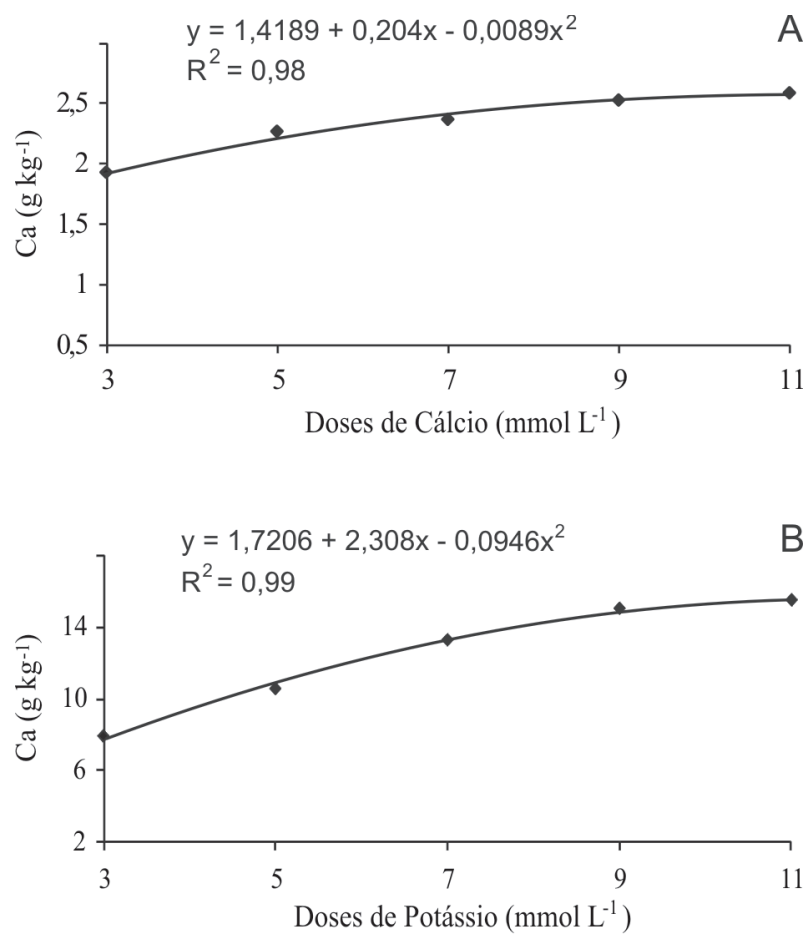

Figura 4.Teor de cálcio no caule (A) e nas folhas (B) de plantas de soja em função das doses de cálcio em solução nutritiva. 

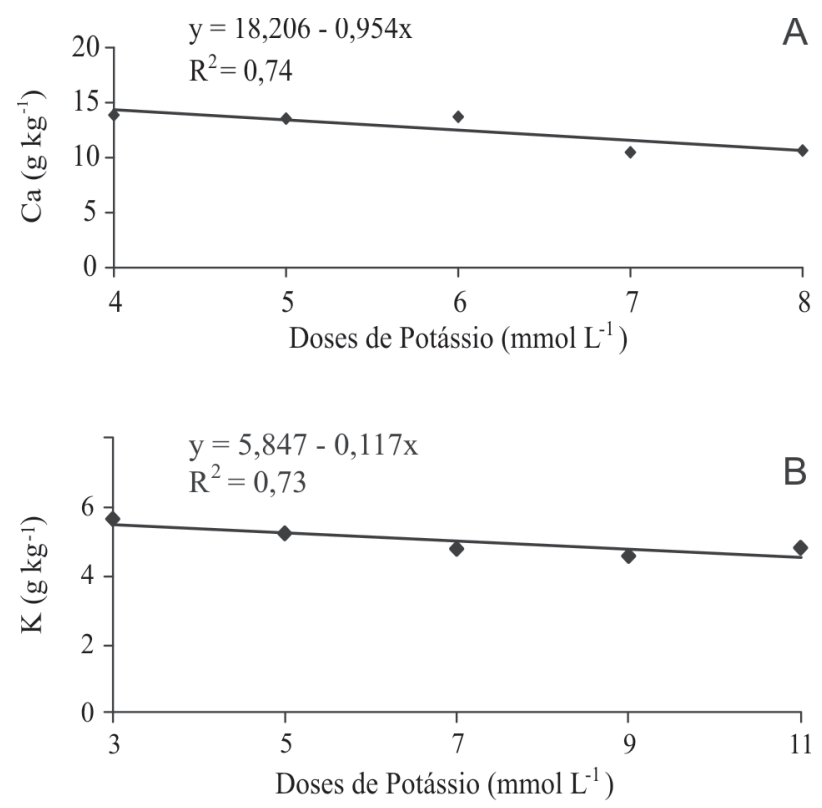

Figura 5. Teor de cálcio em função das doses de potássio (A) e teor de potássio em função das doses de cálcio (B) em plantas de soja cultivadas em solução nutritiva .
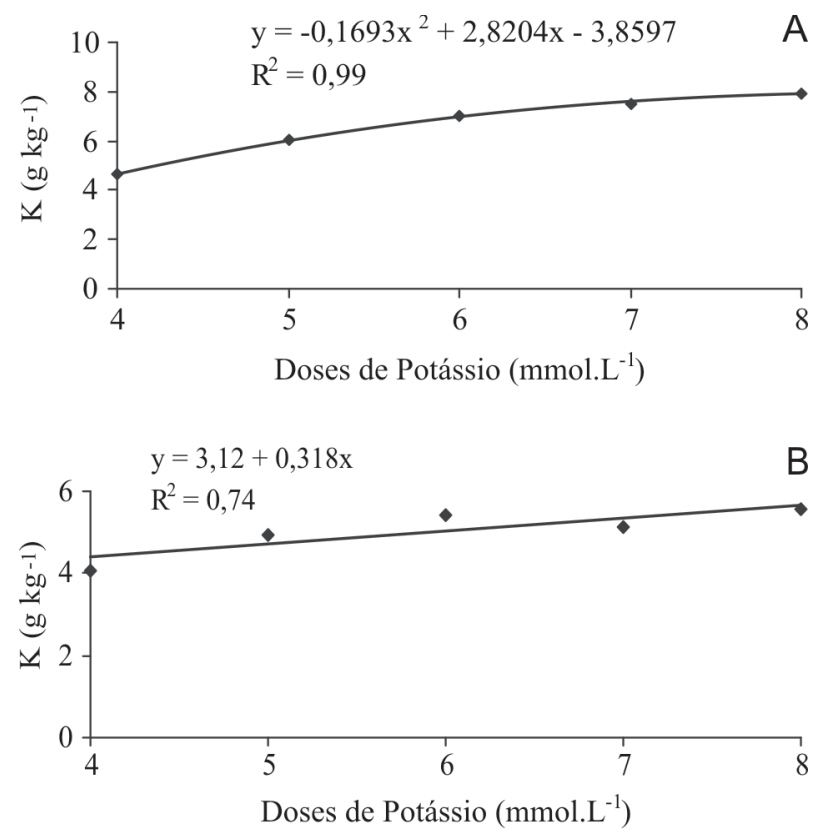

Figura 6. Teor de potássio no caule (A) e nas folhas (B) de plantas de soja em função das doses de potássio em solução nutritiva.

reduzido. O mesmo autor, com o objetivo de estudar a nutrição potássica da soja, em relação à variação dos teores de $\mathrm{Ca}$ e $\mathrm{Mg}$ do solo, observou que a interação das doses de $\mathrm{Ca}$ e $\mathrm{K}$ aplicados influenciou significativamente o teor de $\mathrm{K}$ nas folhas, na época de florescimento. Os maiores teores foliares de $\mathrm{K}$ foram verificados na ausência de $\mathrm{Ca}$, independentemente do nível de $\mathrm{K}$ aplicado. Segundo Malavolta (2006), o efeito do Ca, aumentando ou diminuindo a absorção do K, está na dependência da
A relação $\mathrm{Ca} / \mathrm{K}$ na solução externa. Sempre que a relação é alta, há antagonismo e a absorção de K diminui.

\section{CONCLUSÕES}

A severidade da ferrugem reduziu-se com a elevação do suprimento de $\mathrm{Ca}$ e com as maiores doses de $\mathrm{K}$, sendo influenciada pela interação potássio-cálcio.

Os tratamentos que apresentaram melhor resposta fotossintética foram aqueles com 6 - 5 e 5 - 5 mmol L ${ }^{-1}$ de $\mathrm{K}$ - Ca, respectivamente.

As doses isoladas de $\mathrm{Ca}$ e $\mathrm{K}$ influenciam nos teores desses elementos na matéria seca do caule e das folhas.

Os teores foliares de $\mathrm{Ca}$ e de $\mathrm{K}$ foram reduzidos pela adição de $\mathrm{K}$ e de $\mathrm{Ca}$, respectivamente, à solução nutritiva, corroborando a hipótese de antagonismo ou competição entre esses cátions.

\section{REFERÊNCIAS}

Almeida AMR, Ferreira LP, Yorinori JT, Silva JFV, Henning AA, Godoy CV, Costamilan LM Meyer MC (2005) Doenças da soja. In: Kimati $\mathrm{H}$ et al., (Eds.). Manual de Fitopatologia. São Paulo, Ceres. p.569-596.

Balardin RS, Dallagnol LJ, Didoné HT, Navarini L (2006) Influência do Fósforo e do Potássio na Severidade da Ferrugem da Soja Phakopsora pachyrhizi. Fitopatologia Brasileira, 31:462467.

Basseto MA; Ceresini PC; Valério Filho WV (2007). Severidade da mela da soja causada por Rhizoctonia solani AG-1 IA em função de doses de potássio. Summa Phytopathologica.33:56-62

Bateman DF \& Lumsden RD (1965). Relation between calcium content and nature of the peptic substances in bean hypocotyls of different ages to susceptibility to an isolate of Rhizoctonia solani. Phytopatholoy, 55:734-738.

Bromfield KR (1984). Soybean Rust. Minnesota, The American Phytopathological Society - Monograph $\mathrm{n}^{\circ} 11,65 \mathrm{p}$.

Corden CE (1965) Influence of calcium nutrition on Fusarium wilt of tomato and polygalacturonase activity. Phytopathology, $55: 222-224$.

Delieu T \& Walker DA (1981) Polagraphic measurement of photosynthesic oxygen evolution by leaf discs. New Phytologist, 89:165-178.

Delieu T \& Walker DA (1983) Simultaneous measurement of oxygen evolution and chlorophyll fluorescence from leaf pieces. Plant Physiology, 73:534-541.

Edgington LV \& Walker JC (1958) Influence of calcium and boron nutrition on development of Fusarium wilt of tomato. Phytopathology, 48:324-326.

Garcia Júnior D, Pozza EA, Pozza AAA, Souza PE, Carvalho JG \& Balieiro AC (2003) Incidência e severidade da cercosporiose do cafeeiro em função do suprimento de potássio e cálcio em solução nutritiva. Fitopatologia Brasileira, 28:286-291.

Hoagland DR \& Arnon DI (1950) The water-culture method of growing plants without soil. Berkeley, University of California. $32 \mathrm{p}$.

Huber DM (2002) Relationship between mineral nutrition of plants and disease incidence. In: Workshop - Relação entre nutrição de plantas e incidência de doenças. Piracicaba, Potafos, Anais e Vídeo, vídeo 01. CD-ROM. 
Huber DM \& Arny DC (1985) Interactions of potassium with plant disease. In: Munson RD (Ed.) Potassium in agriculture. Madison, ASA, CSSA, SSA. p. 467-488.

Ito MF, Tanaka MAS, Mascarenhas HAA, Tanaka RT, Dudienas C \& Gallo PB (1993) Efeito residual da calagem e da adubação potássica sobre a queima foliar (Cercospora kikuchii) da soja. Summa Phytopathologica, 19:21-23.

Kochman JK (1979) The effect of temperature on development of soybean rust (Phakopsora pachyrhizi). Australian Journal Agricultural Research, 30:273-277.

McGuire, RG \& Kelman A (1986) Calcium in potato tuber cell walls in relation to tissue maceration by Erwinia carotovora pv. atroseptica. Phytopathology, 76:401-406.

Marschner H (1995) Mineral nutrition of higher plants, 2 nd ed. London, Academic Press. 889 p.

MALAVOLTA, E. (1980) Elementos de nutrição mineral de plantas. Piracicaba, Agronômica Ceres. 251p.

Malavolta E (2006) Manual de nutrição mineral de plantas. São Paulo, Agronômica Ceres. 638 p.

Malavolta E, Vitti GG, Oliveira SA (1997) Avaliação do estado nutricional das plantas: princípios e aplicações, 2 nd ed. Piracicaba, Potafos. 319 p.

Oliveira FA, Carmello QAC \& Mascarenhas HAA (2001) Disponibilidade de potássio e suas relações com cálcio e magnésio em soja cultivada em casa de vegetação. Scientia Agrícola, 58:329-335.

Perrenoud S (1990) Potassium and plant health, 2 nd ed. Bern, International Potash Institute. 363p.

Pascholati SF \& Leite B (1995). Hospedeiro: mecanismos de resistência. In: Bergamin Filho A, Kimati H, Amorim L (Eds.) Manual de fitopatologia: princípios e Conceitos. São Paulo, Agronômica Ceres, v. 1, p. 417-453.
Pozza AAA (1999) Influência da nutrição nitrogenada e potássicoa na intensidade da mancha de olho pardo (Cercospora coffeicola) em mudas de cafeeiro. Dissertação de Mestrado. Universidade Federal de Viçosa, Viçosa, 70 p

Pozza AAA, Martinez HEP, Pozza EA, Caixeta SL \& Zambolim L (2001) Intensidade da mancha de olho pardo em mudas de cafeeiro em função de doses de $\mathrm{N}$ e de $\mathrm{K}$ em solução nutritiva. Summa Phytopathologica, 26:29-34.

Reis EM \& Bresolin ACR (2004) Ferrugem da soja: revisão e aspectos técnicos. In: Reis EM et al. (Eds.). Doenças na cultura da soja. Passo Fundo, Editora Aldeia Norte, p. 55-70.

Rosolem CA, Bessa AM \& Pereira HFM (1993) Dinâmica do potássio no solo e nutrição potássica da soja. Pesquisa Agropecuária Brasileira, 28:1045-1054.

Sfredo GJ \& Panizzi MCC (1990) Importância da adubação e da nutrição na qualidade da soja. Londrina, EMBRAPA, CNPS, 57 p. (EMBRAPA-CNPS. Documentos, 40).

Shaner G \& Finney RE (1977) The effect of nitrogen fertilization on the expression of slow-mildewing resistance in knox wheat. Phytopathology, 70:1183-1186.

Theodoro GF \& Maringoni AC (2006) Efeito de doses de potássio na severidade da murcha-de-curtobacterium em cultivares de feijoeiro comum. Summa Phytopathologica, 32:139-146.

Tuite J (1969) Plant pathological methods: fungi and bactéria. Minneapolis, Burguess. 239p.

Vale FXR (1985) Aspectos epidemiológicos da ferrugem (Phakopsora pachyrhizi Sydow) da soja (Glycine max (L) Merril). Tese de Doutorado. Universidade Federal de Viçosa, Viçosa, 104p.

Ventura CAd'O (1987) Níveis de potássio, cálcio e magnésio em solução nutritiva influenciando o crescimento e composição da soja [Glycine max (L.) Merril], cultivar Paraná. Tese de Doutorado. Escola Superior de Agricultura "Luiz de Queroz", Piracicaba, 65p. 